\title{
Exploring the Success of GMT Technique: Games, Mind-Mapping, and Twitter Hashtags in Teaching Vocabulary in EFL Higher Education Environment
}

\author{
Banan Hassan Alhajaji ${ }^{1}$, Jalila Saleh Algmadi ${ }^{1}$ \& Amal Abdelsattar Metwally ${ }^{1}$ \\ ${ }^{1}$ Faculty of Languages and Translation, King Khalid University, Saudi Arabia \\ Correspondence: Banan Hassan Alhajaji, Faculty of Languages and Translation, King Khalid University, Saudi \\ Arabia.
}

Received: February 20, 2020

Accepted: April 19, 2020

Online Published: April 24, 2020

doi:10.5430/ijhe.v9n3p290

URL: https://doi.org/10.5430/ijhe.v9n3p290

\begin{abstract}
Vocabulary is an essential element of language learning. Wide ranges of vocabulary along with grammatical competence guarantee learners to communicate in the language effectively. This study proposes an edutainment method for learning vocabulary by simply combining education and entertainment. This study aims to gain insights about learners' opinions and perspectives about the use of a technique developed by the researchers as well as how participants feel about their learning. The study investigates the effect of employing Games, Mind-mapping and Twitter Hashtags as the GMT technique, on female Saudi university students' achievement in English vocabulary. The study suggests that this technique which consists of interactive games, cognitive mind-mapping and the exploitation of technology in the form of twitter hashtags, all employed together, constitute a unified framework for activating students' vocabulary learning. The sample in the study consisted of 150 students enrolled in the vocabulary building course during the second semester of the academic year 2018/2019. The participants were asked to respond to the questionnaire and they also took variant assessment tests, then their scores were compared to the results of other students who were not taught vocabulary using the technique in question. The findings ascertain the improvement and significant in the experimental group. In addition, the results reveal that the learners had mostly positive opinions on implementing the GMT technique which facilitated their language learning experience. The researchers conclude that the GMT technique can be an effective tool to promote students' active engagement, motivation, and interaction in vocabulary learning.
\end{abstract}

Keywords: games, mind-mapping, Twitter Hashtags, edutainment, English vocabulary, EFL, teaching methods, motivation, engagement

\section{Introduction}

The importance of vocabulary learning and competence in language proficiency has been a great motivator for language educators to improve new methods for vocabulary instruction. There are many teaching methods which aim to teach vocabulary and different studies which will be reviewed in the review of literature section address the same issue in one way or another. This study attempts to introduce a newly created strategy in teaching. This study employs three tools; games, mind mapping and twitter hashtags, abbreviated as GMT, in the process of teaching vocabulary. The GMT technique is thought to make the teaching and learning of vocabulary more interesting. Unlike the traditional method of learning and teaching, learners are encouraged to be involved in communicative visual activities and technological tools to build their vocabulary. Studies have shown that vocabulary is learned more effectively through a combination of contexts, media and teaching techniques (Medellín, 2008 and Schmitt, 2008). The GMT technique is thought to enable EFL learners to practice what they learn subconsciously in timeless and effortless manner.

\section{Review of the Literature}

Vocabulary is significant for language learning. Although language structure is considered "the skeleton of the language," it is agreed that vocabulary is "the vital organs and flesh" (Harmer, 1998-page number??). Thornburry, in his book entitled How to Teach Vocabulary, (2002:13) states, "Without grammar very little can be conveyed, without vocabulary nothing can be conveyed". Moreover, in his book Vocabulary and Language Teaching, McCarthy says, "vocabulary is the biggest component of any language. If you do not know enough vocabulary you will not be able to 
express yourself adequately" (1990:2). Allen (1983) asserts, "Students who do not learn grammar along with vocabulary will not be able to use the language for communication".

Learning vocabulary is learning to recognize and to use words it requires three steps (Nation, 2001). The first of these is noticing. Learners must notice that a word is new for them, and that it may be useful. The second step requires the learner negotiates meaning interacting with the word, either alone or with the help of another person or of a dictionary. The third step in learning vocabulary is retrieval. The word may be noted and understood, but by using it later, the word will be reinforced. Repetitions are necessary to develop both understanding and fluency, but it is not that mere repetition which enhances learning, but rather the repeated opportunity to retrieve meaning. The third step is creative or generative processing, wherein a previously learned word is met or used in ways that differ from the previous usage (Santana, Santillán and Texon, 2014). According to Hiebert and Kamil (2005), "vocabulary is not a developmental skill or one that can ever be seen as fully mastered. The expansion and elaboration of vocabularies is something that extends across [a] lifetime" (p.2). Consequently, vocabulary building plays a crucial role in the four skills of the language.

Learners must be actively involved in the process of acquiring and building new sets of new vocabulary (Coxhead, 2006). For many EFL learners, learning vocabulary is learning a list of new words with meanings in their native language without use in real context practice. Many learners believe that looking up words in a bilingual dictionary to find their meanings is sufficient to learn vocabulary. However, this traditional way of learning vocabulary has proven not to be very effective for many learners because it depends solely on memorization (Gnoinska, 1998:12?). Decarrico (2001) affirms that words should not be learnt in isolation or by memorization without understanding the meaning. Furthermore, "learning new words is a cumulative process, with words enriched and established as they are met again" (Nation, 2000, p.6).

The following section reviews studies on the use of GMT in teaching vocabulary. The studies reviewed are investigated for the effectiveness of the use of these strategies, each one applied individually, in teaching vocabulary to EFL learners.

\subsection{Games}

Games are one of the techniques that are used to help both teachers and students in getting rid of boredom in the classroom. Games sustain enjoyment and interest in learning and encourage using the language in a creative and engaging way. Bakhsh (2016) investigated teaching English vocabulary to young learners using games, and proved the importance of using games in teaching vocabulary and in what way using them is helpful. This study further provided a practical implication of using games to teach vocabulary that included the implementation of vocabulary games. Finally, it examined the challenges that teachers could face when teaching vocabulary to young learners using games. Furthermore, Gardner (1999) stated that games encompass a number of intelligences such as interpersonal intelligence when they include playing with others, and kinesthetic intelligence when they provide hands-on elements like cards. In his book entitled Elementary Vocabulary Games, Hadfield (1998:4) said, "A game is an activity with rules, a goal, and element of fun, which is divided into two kinds; competitive games, in which players or teams race to be the first to reach the goal, and cooperative games, in which players or teams work together towards a common goal". Lee (1995:35) listed several main advantages when games are used in the classroom, including "a welcome break from the usual routine of the language class", "motivating and challenging" "effort of learning", and "language practice in the various skills". Halliwell (1992) argued that teachers should provide young learners with a communicative atmosphere due to the creative language skill young learners bring into the classroom. As such, games are extremely important. Not only they are fun, but also they create the desire to interact, communicate and result in creativity. Additionally, Rixon (1981) indicated that understanding games will help teachers in finding and creating games that make their students learn while they play. This study, also, addressed the advantages and disadvantages of using games in teaching EFL vocabulary.

\subsection{Mind-Mapping}

Mind mapping is a pedagogical technique which involves visual realization of ideas. It can be used in different learning and communicative arenas. People make use of various colors, images, symbols, shapes and errors, etc. to associate and connect ideas and visualize facts. The strong visual appeal of mind maps can speed up the learning process and help students to memorize and recall information effectively because it shows the overall structure (Brinkmann, 2003). In addition, (Buzan \& Buzan, 2000) illustrate that the more personalized the mind maps, the more easily the learner can retrieve information.

Al-Jarf (2011:51) stated that mind-mapping enables students to better organize, prioritize, and integrate material 
presented in a course. As stated by Li,Yang \& Chen (2010), mind-mapping is useful for the building of knowledge and understanding of ideas association and vocabulary learning. It has been studied in areas such as: spelling, categorization, synonyms and free association. Alamsyah (2009) explained that mind maps work well as their visual design enables students to see the relationship between ideas, and encourages them to group certain ideas together as they proceed. Thornbury $(2002,18)$ says, "acquiring a vocabulary requires not only labeling but categorizing skills". In this study, mind mapping has been chosen as a technique to help the students in memorizing the words which are expected to improve their vocabulary proficiency by memorizing easily. Buzan (1993:1) states that mind mapping is a powerful graphic technique, which provides a universal key to unlock the potential of brain. From the above review, it is clear that mind mapping is a significant technique to improve study skills, problem solving, critical thinking and memory recall.

\subsection{Twitter Hashtags}

Twitter is a free, online microblogging site where users send texts- known as tweets- to a network of followers. The length of tweets is constrained to 140 characters, but links and images are allowed. The default setting is public, so one can 'follow' the postings of anyone listed on the site. These postings are saved on the sender's personal page, and are known as a Twitter feed. Most contemporary mobile phones have an application which can send or receive posts (Jansen, Zhang, Sobel \& Chowdury, 2009).

Twitter hashtags could be a significant pedagogical tool for teaching the students of the twenty first century. Prensky (2001) coined the terms 'Digital Natives' and 'Digital Immigrants' in reference to the different degrees of relationship between individuals and technology. 'Digital Natives' are those who largely rely on technology. Our students are 'digital natives' since they are "all native speakers" of the digital language of computers, and the Internet". Unlike "digital natives", "digital immigrants" learn - like all immigrants, some better than others - to adapt to their environment. The "digital immigrant accent" can be seen in such things as turning to the Internet for information second rather than first" (Prensky, 2001: 1-2). Since our students are "Digital Natives", using twitter hashtags, and other technologies, could increase students' motivation and interest in learning.

Bake-Plock (2009, p. 36) shared on his blog his own positive experience in using Twitter in the classroom where he affirmed "I see Twitter as an excellent resource for assessing several skills that are fundamental to learning and living such as: the ability to make mistakes and immediately get positive critical feedback". This article contains a list of the best practices that can be used for Twitter to enhance the classroom. This list includes such items as building the students' vocabulary through open-ended questions and discussion and strengthening their grammar by providing them with immediate corrections. Welch \& Bonnan-White (2012) assert that using Twitter inside the classroom helped to increase students' engagement. They highlight that tweeting about an opinion or an answer to a multiple choice question inside the classroom was enjoyable and students were motivated and engaged in the learning process. Another study about using Twitter outside the classroom is conducted by Al-Otabi (2013). Her study aims to investigate the effectiveness of Twitter on academic achievement and the construction of cooperative learning skills among students.

Twitter as a microblogging platform is used in an EFL context in the study by Borau, Ullrich, Feng and Shen (2009). Chinese students who were learning English as a foreign language participated in the Twitter activity that was embedded to their English listening and speaking course curriculum for seven weeks. At the end, the participants were given a bilingual questionnaire about their usage of and opinion on Twitter. Results indicated that the students had positive opinions with respect to communication in target language on Twitter and it was found to be a suitable tool to train communicative and cultural competence.

Junco et al. (2011) confirmed that, in their study, when an experimental group used Twitter and was compared to a control group, the Twitter-using group achieved higher levels in GPA tests and also reported higher motivational engagement than the control group.

The above analytical review of literature of all three techniques sheds light on the use of GMT in teaching vocabulary. Previous literature indicates the effectiveness of different methods in increasing students' motivation, interest and cooperative learning. In this study, the GMT is presented as a comprehensive technique which relies on the use of games, mind mapping and twitter hash tags for teaching and learning vocabulary. The following section highlights the hypothesis, questions of the paper and the methodology employed to answer the questions.

\section{Hypothesis}

Acquiring English vocabulary by using games, creating mind-mapping and employing hashtags is more effective than the traditional techniques such as a verbal technic or visual to describe the meaning of a new words by using the white board and translation in a classroom of English language teaching among Saudi university female learners. 


\section{Research Questions}

1- are there any significant differences between the impact of traditional teaching techniques and using the GMT technique?

2- Does using GMT technique in teaching vocabulary have a positive effect on students' vocabulary achievement?

3. In what way does the GMT technique support motivation and creativity?

\section{Methodology}

The data collected for this study were obtained via classroom observation; it is a description of what lecturer used for teaching in the classroom. Furthermore, the lecturer used an online questionnaire by providing a set of questions intended the students' evaluation of the different techniques are used in teaching vocabulary. They achieved the result of the improvement of acquiring English vocabulary by using different techniques by the lecturer in L2 environment by improving their results as we can investigate it in the discussion section. The pattern of this study is quantitative experimental research.

\subsection{Participants}

The participants for this study were 517 female students enrolled in a vocabulary building 2-course, upper-intermediate level at King Khalid University in Abha, Saudi Arabia. The students ranged in age from 21 to 23. They were in their second year at university. The data was collected in the first semester of the 2018-2019 academic year. Five intact sections were participating in this study.

\subsection{Instruments}

The instruments used were class observation and a questionnaire. The researcher used various techniques for acquiring English vocabulary in the vocabulary building course and the purpose is to make this course much easier for L2 Saudi learners in a higher education environment at King Khalid University. The instruments were conducted by teaching a new vocabulary were games, social media such as twitter, mind-mapping and a vocabulary test. You also used games? A vocabulary test? You should describe them all in the instruments section.

\subsubsection{The First Technique}

The first technique is a game called "don't say it card". It is a game that is based on the variety of vocabulary covered in each unit. One of the student pick up one of the cards and try to explain them to other students by creating new sentences and synonyms to help other students to catch the specific word that is provided in the card. This strategy allows students to use different synonyms or antonyms for guessing the specific words in the card which can expand their vocabulary.

\subsubsection{The Second Technique}

The second technique is drawing mind-mapping to memorize a newly learned vocabulary which can motivate students to use these lexical items in their spoken and written language. According to Edward (2011) and McGriff (2007), mind-mapping has the ability to make a balance in the brain and help to organize students' thoughts. Also, mind-mapping improves students' creativity, and they will learn and memorize faster.

\subsubsection{The Third Technique}

The third technique is using "Twitter Hashtag". The researcher asked the students in the classroom to use Twitter Hashtags to post the new words and their definitions, with examples, and those words already covered in the class. The reason for carrying out this activity is to know the uses of these words by using different methods, for instance, they will focus on the part of speech, improve their spelling, and how they can use them into different sentences. Ally (2012) assured that using a social media such as twitter is an effective way to improve students' attention, and their engagement. This way allows students to share their ideas and questions with the lecturer at any time and place without adhering solely to the limited time and place of the traditional classroom.

\section{Data Analysis}

\subsection{Quantitative Analysis Using Student Scores}

In order to answer the research questions and measure the impact of GMT techniques in teaching vocabulary, student scores were used to measure their proficiency in vocabulary acquisition. The quantitative data were analyzed using SPSS, which was helpful in developing a more in-depth analysis of student performance. First, the analysis of the collected data focused on finding the means of the control and experimental groups. Then, an independent sample $t$-test was carried out to investigate the significant differences between the traditional teaching methods (i.e. markers and a 
whiteboard) and the GMT technique (i.e. games, mind mapping and Twitter hashtags). Finally, the $P$-value was determined to find the significance level of the differences between the represented samples. The results were considered statistically significant if the $P$-value was below $0.05(p<0.05)$.

\subsection{Questionnaire}

The electronic questionnaire was analyzed using SPSS. Among the 218 students that made up the experimental sample, 165 nonobligatory participants evaluated the GMT technique and its effectiveness in helping them master vocabulary. In the questionnaire, Likert scale statements were coded from 1 to 5 , with 1 representing strong disagreement and 5 strong agreements (strongly disagree $=1$, disagree $=2$, neutral $=3$, agree $=4$, strongly agree $=5$ ). Similar coding was used to analyze the questions requiring yes or no answers (with yes $=1$ and no $=0$ ). In addition, an open-ended question was included to measure students' observations and motivations in learning vocabulary using the GMT technique. This question was analyzed using inductive coding (i.e. the answers were coded only after the data were collected), the purpose of which was to minimize the possibilities for bias in the study.

Furthermore, the questionnaire was designed and distributed to the students before the test in order to exclude the possibility that the students' test scores might influence their evaluation of the teaching methods (GMT technique). Moreover, the questionnaire was prepared and distributed before the research was organized and written up.

\section{Results and Discussion}

\subsection{Student Scores}

Research question 1: Are there any significant differences between the impact of traditional teaching methods and the use of the GMT technique?

Table 1. Statistics Analysis of the Control Group and Experimental Group

\begin{tabular}{|c|c|c|c|}
\hline \multicolumn{2}{|l|}{ Determiners } & Control Sample & Experimental Sample \\
\hline \multicolumn{2}{|l|}{ Number } & 299 & 218 \\
\hline \multicolumn{2}{|l|}{ Mean } & 67.89 & 84.06 \\
\hline \multicolumn{2}{|l|}{ Maximum } & 100 & 99 \\
\hline \multicolumn{2}{|l|}{ Minimum } & 29 & 42 \\
\hline \multicolumn{2}{|l|}{ Std. Deviation } & 17.022 & 10.265 \\
\hline \multicolumn{2}{|l|}{ Std. Error Mean } & 0.984 & 0.695 \\
\hline \multicolumn{2}{|l|}{$\mathrm{t}$} & -12.471 & -12.471 \\
\hline \multicolumn{2}{|l|}{ Mean Difference } & -16.173 & -16.173 \\
\hline \multicolumn{2}{|l|}{ Sig (2-tailed) } & 0.000 & 0.000 \\
\hline \multirow{2}{*}{$\begin{array}{l}\text { 95\% Confidence Interval of the } \\
\text { Difference }\end{array}$} & Lower & -18.721 & -18.541 \\
\hline & Upper & -13.625 & -13.806 \\
\hline
\end{tabular}

There were 517 participants in total, who were divided into a control group of 299 students and an experimental group of 218 students. As can be seen in Table 1, a comparison of the means and standard deviations of each sample yields $\mathrm{M}=67.89$ and $\mathrm{SD}=17.022$ for the control group and $\mathrm{M}=84.06$ and $\mathrm{SD}=10.265$ for the experimental group. The standard deviations are far beyond the means of both groups, which indicates significant variation in the scores within each group.

The result of an independent sample $t$-test calculation was utilized to investigate the significant differences in the scores obtained between the group taught using the traditional methods of teaching vocabulary and the group taught using the GMT techniques. The $t$-test value was -12.471 , which was less than the mean $(-16.173)$ of both sections. However, the result of the 2-tailed analysis (0.000) was statistically significant as it was less than the accepted threshold for the $P$ value $(0.000<0.05)$. Moreover, the confidence interval of differences in the control group was between -18.721 and -13.625 , and in the sample group it was between -18.541 and -13.806 . Thus, the confidence interval was below zero in both groups. However, the results of the $t$-test and 2-tailed analysis indicate significant differences between the two sections in learning English vocabulary. 
Research question 2: Does the use of the GMT technique to teach vocabulary have a positive effect on students' acquisition of vocabulary?

In order to determine the general proficiency levels of the two groups, learners' test results were categorized into five groups as follows: A for excellent (with a score of 90-100), B for very good (80-89), C for good (70-79), D for pass (60-69) and $\mathrm{F}$ for fail (below 59). The group mean was considered the main indicator of the vocabulary acquisition level of each sample. The mean for the control group was 67.89 , while for the experimental group it was 84.06. Thus, the average proficiency level of the control sample was "pass" (D), while the average of the scores obtained among individuals in the experimental sample yielded a level of "very good" (B). This suggests that the use of GMT methods had a positive impact in helping the students learn English language vocabulary. This supports previous results from Coxhead (2006), who described the benefits of student engagement in achieving better learning outcomes.

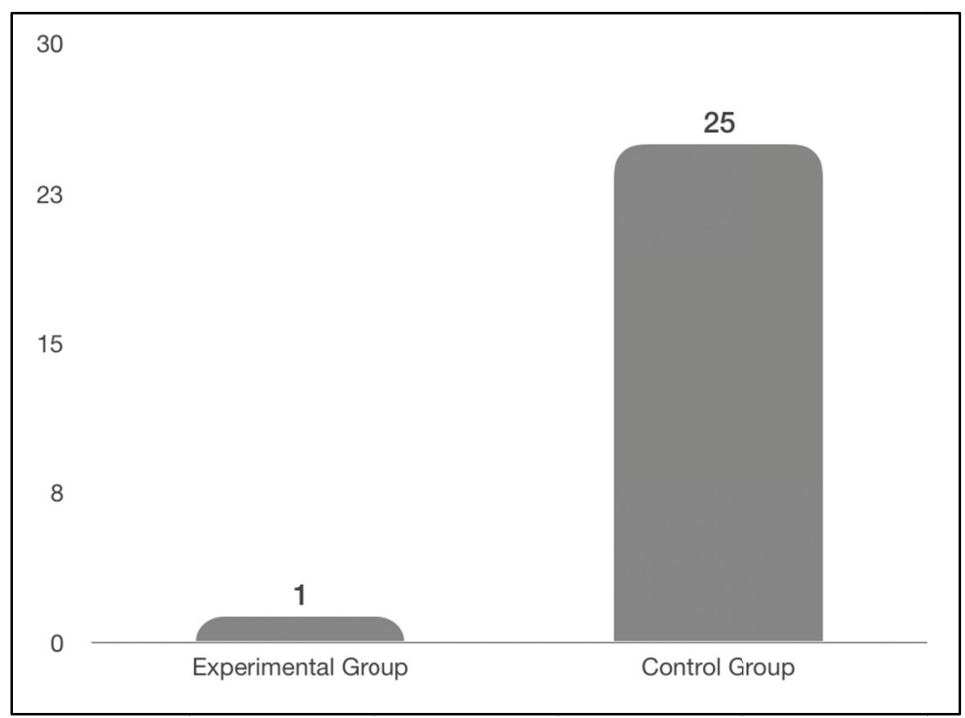

Figure 1. Percentage of Failed Students

The number of failed students in each sample - those who received scores below 59-was also counted as an indication of the GMT method's effectiveness. The data displayed in Figure 1 show that the total number of students who failed the test after studying English vocabulary using traditional methods of teaching and learning (i.e. white board and markers, translation and word lists) surpasses the number who failed after learning via GMT techniques. Twenty-five percent of participants from the control group failed to pass the test, in contrast with only 1.3 percent of students in the experimental group. This sharp contrast in results can serve as a solid piece of evidence supporting the effectiveness of GMT techniques.

The results of these analyses have supported the expectation that there would be a distinction in learner proficiency between the student group exposed to GMT techniques and the group taught vocabulary using more traditional ways of teaching. By comparing the number of successful and failed students in each sample, one can see that the use of the GMT method is effective in supporting the process of learning English vocabulary for foreign language learners.

\subsection{Questionnaire}

Research question 3: In what way does the GMT technique support motivation and creativity?

The students' responses to the questionnaire were collected to measure the effects of GMT techniques on students' motivation to learn English vocabulary. The students in the experimental sample described various understanding levels during their experiences in learning English vocabulary knowledge. From this group, $44.8 \%$ answered that it was excellent, $50.9 \%$ replied that it was good, $3.7 \%$ said that it was fair and $0.6 \%$ said that it was poor. The open-ended question was included to investigate the students' motivation in using GMT methods to learn vocabulary. This question was answered by 49 participants, who emphasized that they liked the experimental method of learning vocabulary for many reasons. Foremost, they thought the classes were interesting and they liked practicing English vocabulary through the GMT technique. About 30 participants added that a sympathetic language instructor had supported and motivated them to learn. This is exactly in line with the results of Gozcu and Caganaga (2016), who showed that using games in the EFL classroom created a relaxed atmosphere and increased learners' motivation. 
A more in-depth explanation is supported by the analyses of the following three parts of the questionnaire, which clarify the students' perspectives on the effectiveness of GMT techniques.

\subsection{1 "Don’t Say It” Card Game}

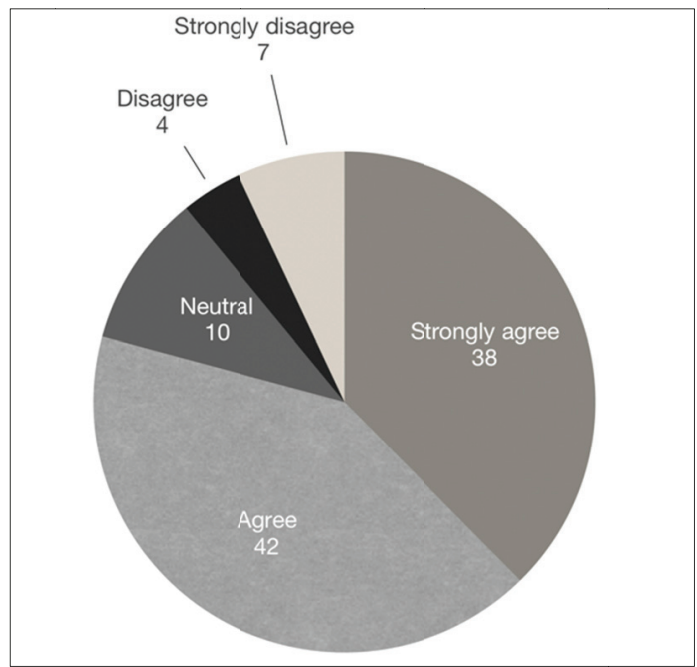

Figure 2. Percentage of student agreement on the effectiveness of use of the "don't say it" card game

The GMT method recommends using games in the classrooms to teach foreign languages. About $80 \%$ of the participants agreed that the game used, the "don't say it" card game, was significantly effective in helping them learn English vocabulary and retrieve new words (Figure 2). Likewise, 94.5 percent said the game was helpful to them, and 88.3 percent recommended that other foreign language instructors use games in teaching. It was also asserted that this fun teaching method could be used to decrease anxiety felt by students, such as when they feel insecure or afraid of being corrected by the teacher, which is considered to be the main factor hindering the learning process. This is in line with previous research conducted by Y1ltanlılar, Çağanağa and Cyprus (2015), who found that the use of games in the classroom will minimize negative feelings and create an enjoyable atmosphere. Furthermore, games create a cooperative atmosphere to practice the learned vocabulary in a setting in which the target language is used. This is considered to be one of the advantages of learning while playing (Rixon, 1981)

\subsubsection{Writing Notebooks and Mind Maps}

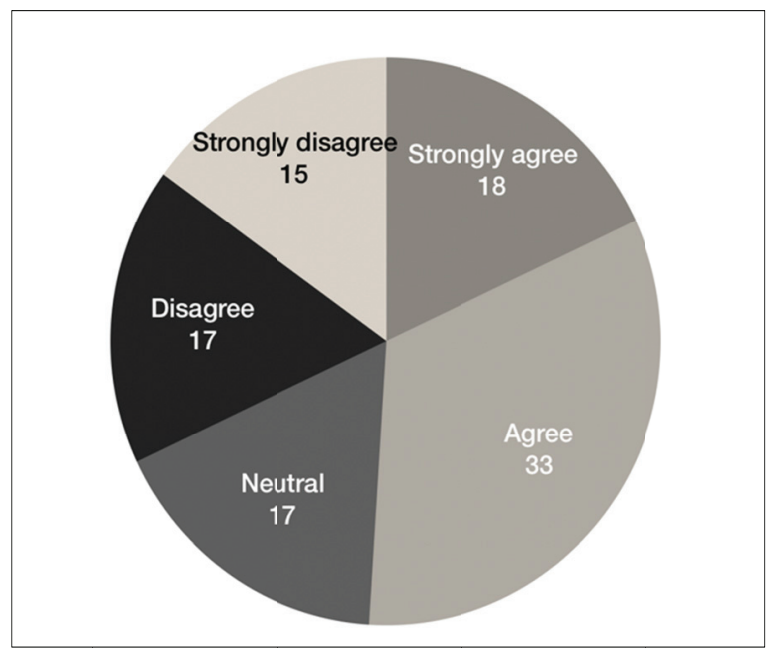

Figure 3. Percentage of student agreement on the effectiveness on use of notebooks and mind maps

After the "don't say it" card game, the use of notebooks and mind maps ranked second among students' preferred GMT techniques. There was more variation among students' answers regarding the effectiveness of these two techniques. Approximately half of the participants declared them to be helpful. In contrast, about one third of the participants 
contradicted this claim (Figure 3). In order to understand the factors underlying the students' evaluations, participants were asked to mention all the negative aspects of these methods. Some students replied that preparing a notebook was time consuming, and that it was difficult to study, practice and remember the words in the notebook in a short period of time. The other reason students provided was they were extremely busy studying for exams and completing assignments in their other courses and found insufficient time to make notebooks and mind maps. Despite their hesitation in wholeheartedly accepting these techniques, $66.3 \%$ of the participants recommended that other language instructors use them in teaching.

\subsubsection{Twitter Hashtags}

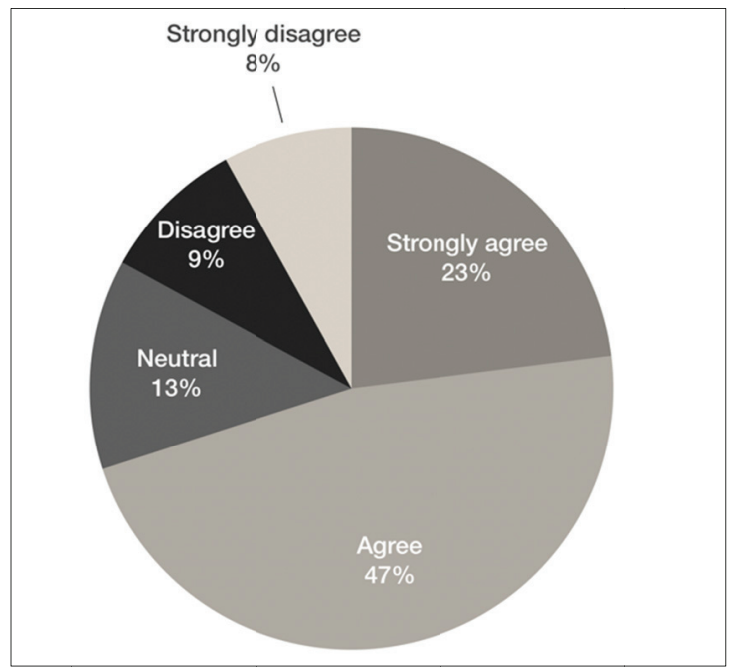

Figure 4. Percentage of student agreement on effectiveness of Twitter hashtag use

As can be seen in Figure 4, the students agreed overall that social media, particularly the use of Twitter hashtags, provided effective tools for learning vocabulary outside the classroom. About three quarters agreed on the crucial significance of practicing the learned vocabulary, and 85.9 percent confirmed that Twitter was helpful. Moreover, 82.2 percent of the participants mentioned that they had used Twitter hashtags more than once as part of their language learning. These results confirmed the finding of Junco et al. (2011) that using Twitter helped students obtain higher grade point averages and increased their motivation.

From this standpoint, the GMT method (specifically the use of games, mind mapping and Twitter hashtags) can be considered an effective set of instruments for teaching and learning English vocabulary, and the data analysis yielded answers to this study's research questions.

The effectiveness of GMT methods is supported by the high scores achieved by the students in the experimental group. Moreover, the incorporation of GMT's fun learning techniques into students' language practice increased the learners' proficiency and enhanced their ability to use the learned vocabulary in speaking and writing.

Medellin and Schmitt (2008) argued that a variable combination of context, media and teaching methods collaborate to enhance the vocabulary learning process, and this experience with GMT methods at King Khalid University support their argument. Most participants found the GMT techniques to be enjoyable, and they affirmed that the strategy underlying these techniques was interesting and supported their learning by increasing their opportunities to practice the language. Therefore, it is recommended that foreign language instructors be creative in delivering their lessons and use these recently approved methods in teaching vocabulary.

In short, the results demonstrate three significant findings for GMT techniques. First, classroom games are an enjoyable method in language learning and are recommended to accelerate vocabulary learning. The use of games has various advantages, the most important being that it helps create learning conditions that allow students to learn and practice the language without feeling self-conscious. In addition, the use of fun methods of teaching vocabulary impacts student proficiency and interest in practicing the language, which in turn can accelerate vocabulary acquisition. Second, there should be sufficient time provided to students so that they can implement the new vocabulary in communication and also so that they can design creative and useful mind maps to help them retrieve, analyze and make connections between the learned vocabulary words and their uses (Brinkmann, 2003). Finally, it is recommended that 
instructors encourage their "digital native" students (Prensky, 2001: 1-2) to connect with the learning process when outside the classroom by utilizing Twitter hashtags to practice new vocabulary.

To build on the current level of understanding of GMT techniques, other second language instructors should apply these methods with different types of student groups (like including both genders male and female) or with larger groups. In so doing, it is recommended that they administer a pre-test and post-test as a parameter to measure the development of the students' proficiency after using this simple and fun method of teaching.

\section{References}

Alamsyah, M. (2009). KiatJituMeningkatkanPrestasiDengan Mind Mapping.Yogyakarta: :MitraPelajar

Al-Jarf, R. (2011). Teaching spelling skills with a mind-mapping software. Asian EFL Journal Professional Teaching Articles, 53, 4-16.

Allen, V. (1983). How to Teach Vocabulary. England: Longman.

Ally, M. (2012). Student Attention, Engagement and Participation in a Twitter-friendly Classroom, in ACIS 2012. Location: Proceedings of the 23rd Australasian Conference on Information Systems, ACIS, 1-9.

Al-Otabi, N. (2013). The Effectiveness of Social Networking Twitter (microblogging) on Academic Achievement and the Developing the Cooperative Learning Skills for Female Students in Second Grade Secondary in Computer Curriculum. E-learning \& Distance Education.

Bakhsh, S. (2016). Using Games as a Tool in Teaching Vocabulary to Young Learners. English Language Institute, King Abdul Aziz University, Jeddah, Saudi Arabia. Retrieved 20, October, 2019 from: https://doi.org/10.5539/elt.v9n7p120

Borau, K., Ullrich, C., Feng, J., \& Shen, R. (2009). Microblogging for language learning: Using twitter to train communicative and cultural competence. Proceedings of International Conference on Web Based Learning-ICWL 2009 (pp. 78-87). Berlin: Springer-Verlag. https://doi.org/10.1007/978-3-642-03426-8_10

Brinkmann, A. (2003). Mind Mapping as a Tool in Mathematics Education. Mathematics Teacher. National Council of Teachers of Mathematics NCTM, 96(2), 96-101.

Buzan, T., \& Buzan, B. (2000). The mind map book. London: BBC Books.

Buzan, T. (1993). The Mind Map Book. London, BBC Books

Edward, L. (2011). Advantages and disadvantages of mind maps.

Gardner, D. (1999). Vocabulary acquisition through reading: assessing the Lexical composition of theme-based text collections in upper-elementary education. Doctoral dissertation. Northern Arizona University.

Gnoinska, A. (1998). Teaching vocabulary in colour. English Teaching Forum, 36(3), 12-15.

Gozcu, E., \& Caganaga, C. K. (2016). The Importance of Using Games in EFL Classrooms. Cypriot Journal of Educational Sciences, 11(3), 126-135. https://doi.org/10.18844/cjes.v11i3.625

Hadfield, J. (1998). Elementary Vocabulary Game. England: Longman.

Halliwell, S. (1992). Teaching English in the Primary Classroom. New York: Longman

Harmer, J. (1998). How to Teach English: An Introduction to the Practice of English Language Teaching. London: Longman

Hiebert, E. (2005). Teaching and Learning Vocabulary Bringing Research to Practice. University of California, Berkeley, Michael L. Kamil Stanford University, Lawrence Erlbaum Associates, Publishers Mahwah, London. https://doi.org/10.4324/9781410612922

Jansen, B. J., Zhang, M., Sobel, K., \& Chowdury, A. (2009). Twitter power: Tweets as electronic word of mouth. Journal of the American Society for Information Science and Technology, 60, 2169-2188. Retrieved 20, October, 2019 from https://doi.org/10.1002/asi.21149

Junco, R., Heiberger, G., \& Loken, E. (2011). The effect of Twitter on college student engagement and grades. Journal of Computer Assisted Learning, 27(2), 119-132. Retrieved 20, October, 2019 from https://doi.org/10.1111/j.1365-2729.2010.00387.x

Lee, S.K. (1995). Creative games for the language class. Forum, 33(1), 35. Retrieved 20, October, 2019 from http://eca.state.gov/forum/vols/vol33/no1/P35.htm 
Li, M., Yang, Y., \& Chen, H. (2010). Using Mind Maps as a Strategy for Vocabulary Acquisition in Chinese Universities. In Computational Intelligence and Software Engineering (CiSE), 2010 International Conference on (pp. 1-3). IEEE. https://doi.org/10.1109/CISE.2010.5677128

McCarthy, M. (1990). Vocabulary (Language Teaching: A Scheme for Teacher Education) (12-01) Paperback Bunko $-1836$

McGriff, S. (2007). Instructional systems program. Pennsylvania: Pennsylvania State University.

Nation, I. (2000). Vocabulary. In M. Byram (ed.) Routledge Encyclopaedia of Language Teaching and Learning. Routledge.

Nation, I. (2001). Learning Vocabulary in Another Language. Cambridge: Cambridge University. https://doi.org/10.1017/CBO9781139524759

Prensky, M. (2001). Digital natives, digital immigrants. On the Horizon, 9(5). Retrieved 20, October, 2019 from https://doi.org/10.1108/10748120110424816

Rixon, S. (1981). How to use games in language teaching. London: Macmillan.

Santana, J., Santillán, A., \& Texon, F. (2014). Learning Vocabulary Through Twitter. 7th International Conference of Education, Research and Innovation: Seville, Spain

Thornburry, S. (2002). How to Teach Vocabulary. England: Longman.

Welch, B. K., \& Bonnan - White, J. (2002). Twittering to increase student engagement in the University Classroom. Knowledge Management \& E-learning: An International Journal, 4(3).

Yıltanlılar, A., Cyprus, N., Çağanağa, Ç. K., \& Cyprus, N. (2015). The Perceptions of EFL Teachers on the Impact of the Usage of Code-Switching in EFL Classroom Management. Open Access Library Journal, $2(11), 1$. https://doi.org/10.4236/oalib.1101961 